ЭКОНОМИЧЕСКИЕ НАУКИ

\title{
RESEARCH ON THE CROSS-CULTURAL MANAGEMENT OF CHINESE ENTERPRISES IN \\ TRANSITIONALMERGERS AND ACQUISITION: GEELY'S ACQUISITION OF VOLVO
}

DOI: 10.31618/ESU.2413-9335.2021.3.85.1330

Yan Kaifeng

Candidate of Institute of Industrial Management,

Economics and Trade Peter the Great Saint-Petersburg Polytechnic University

\begin{abstract}
Based on the previous research on the integration of $\mathrm{M} \& \mathrm{~A}$ culture, this paper discusses the case of Geely Group's acquisition of the Swedish luxury car brand Volvo. We study the integrating process to make the enterprise manager realize the importance of cultural integration and provide them the reference about cross-border merger and acquisition to improve the success rate of $\mathrm{M} \& \mathrm{~A}$.
\end{abstract}

Keywords: Geely, Volvo, transnational mergers and acquisition, cultural integration

\section{INTRODUCTION}

There are currently more and more cross-border mergers and acquisitions, which has become a meaningful way to achieve internationalization and optimal resource allocation for global companies. Chinese enterprises should not only seek development at home but also move towards internationalization. In this process, due to the differences between national culture and corporate culture, cross-cultural conflicts are likely to occur and affect enterprises' business activities. The rapid development of overseas M\&A has become an important symbol for Chinese enterprises to enter the world stage. Under the guidance of the national "One Belt And One Road" policy, it is particularly urgent to solve the problem of cultural conflicts arising in the process of state-owned enterprises' cross-border mergers and acquisitions. However, most of the current research results focus on developed countries' mergers and developing countries' acquisitions. The case studies of Chinese domestic enterprises' mergers and acquisitions of Europe and America are not in-depth enough. Transnational cultural differences generally have become national, corporate, and individual levels. It is necessary to carry out detailed analysis and research on the acquirer and the merged party's national cultures and corporate cultures, find out their cultural similarities and differences, and then adopt reasonable and scientific integration mode and countermeasures to solve cultural conflicts.

From the perspective of corporate culture, the article analyzes and studies the case of Geely Group's acquisition of the Swedish luxury car brand Volvo and its realization of the "snake swallowing elephant." At the beginning of the merger, Geely recognized the cultural differences with Volvo, attach importance to cultural integration with Volvo, and build an organizational culture of mutual respect and trust. The results show that Geely Auto has successfully achieved transformation with Volvo. Because of this M\&A, Volvo has revitalized, and its corporate competitiveness has significantly enhanced. Therefore, the study of this M\&A case from the perspective of corporate culture integration has essential reference significance.

\section{RESEARCH IDEAS AND METHODS}

The research method used in this paper is the international case study method. Based on the clear research motivation and purpose, the idea of this paper includes three steps:

Step1: Collecting the current research findings on the theory of cultural integration of M \& A enterprises

Step2: We analyze this case's whole process in a comprehensive, in-depth, and systematic way.

Step3: Providing valuable suggestions and methods to Chinese enterprises.

This paper chooses the case of Geely's acquisition of Volvo as the subject of study. In the case description, I will give a complete description of the integration process of this case and underline the research subject of this paper by striving to be truthful, comprehensive, thorough, and objective and avoiding the subjectivity of the individual, and pay attention to the realism and vividness of the plot in the description.

In the case report, a comprehensive, in-depth, and systematic analysis of the case was carried, focusing on the application analysis of management theory and paying particular attention to the case material's relevance and the analysis report.

In this article's conclusion, we briefly consider the critical points of cultural integration management of cross-border mergers and acquisitions.

\section{LITERATURE REVIEW}

It isn't easy to define culture so far, which could be universally accepted; different scholars have given various statements and definitions of culture from their research perspectives. Among them, Hofstede, the director of the Dutch Institute of Cultural Cooperation, has defined culture from management psychology, which most cultural and management scholars have recognized: culture is the collective programming of the mind used to distinguish a group. There will always be particular behavior, ways of thinking, and perspectives of seeing things unique to this group's members. People learn the culture of a group by becoming one of them. People often insist on the group's values and beliefs they belong to, consciously or unconsciously, but usually do not realize that their values and beliefs profoundly impact them. People only truly perceive their own culture when communicating with people from other cultures. 
As a subculture, corporate culture has distinct national and national cultural characteristics. The factors such as the company's unique growth background and growth process make corporate culture different from other companies in the country.

The characteristics of the culture described above determine that it is challenging to integrate corporate culture in mergers and acquisitions, but the contribution is enormous if the integration is successful. The vast potential influence of culture makes post-merger integration directly affect corporate mergers and acquisitions' success or failure as one of the most critical factors of post-merger integration. The integration of corporate culture has attracted the attention of a large number of scholars. They generally carried out the literature on cultural integration in mergers and acquisitions is along two main lines. The first is to in-depth internal research on which cultural factors affect organizational performance and the extent to which it affects organizational performance. The second is the choice of cultural adaptation model. In the face of the acquirer's different corporate cultures and the acquired party, which cultural adaptation model can achieve the best integration effect.

\section{CULTURAL DIFFERENCE BETWEEN CHINA AND SWEDEN}

In analyzing Geely and Volvo's cultural differences, this article uses Hofstede's cultural dimension theory to explore China and Sweden's cultural differences. According to the idea of Hofstede, there are six fundamental dimensions of cultural value.

\section{China $x$ Sweden $x$}
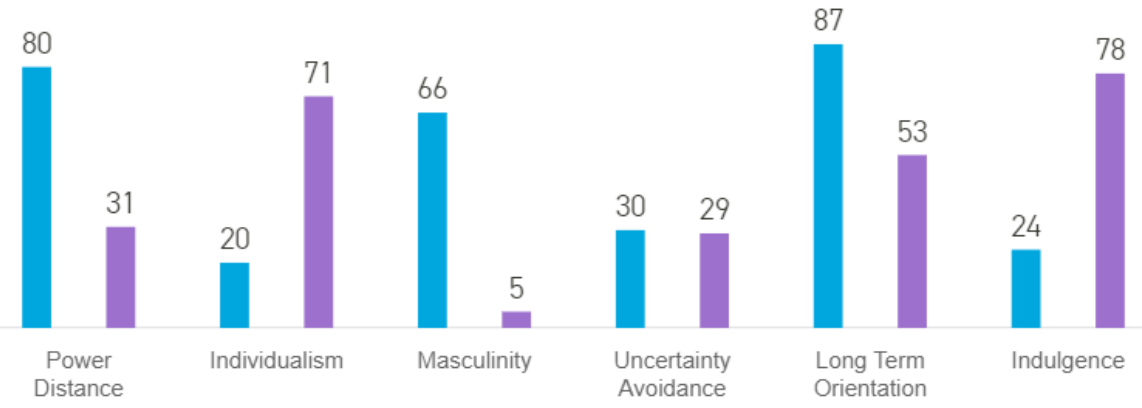

Figure1. The cultural comparison between China and Sweden

Power distance : The score of China high on this dimension (80). It means in China, the subordinatesuperior relationship tends to be polarized, and there is no defense against power abuse by superiors. While Sweden scores low on this dimension (score of 31), the following characterizes the Swedish style: Independence, the hierarchy for convenience only, equal rights, superiors accessibility, coaching leader, management facilitates and empowers[8].

Individualism\&Collectivism : At a score of 20, China is a highly collectivist culture where people act in their interests and not necessarily themselves. However, with a score of 71, Sweden is an Individualist society, which means there is a high preference for a loosely-knit social framework. Individuals are expected to take care of themselves and their immediate families only [8].

Masculinity\& Femininity: At 66 , China is a Masculine society -success-oriented and driven. At the same time, Sweden scores five on this dimension and is, therefore, a Feminine society. In Feminine countries, it is essential to keep the life/work balance, and you make sure that all are included[8].

Uncertainty avoidance: At 30, China has a low score on Uncertainty Avoidance. The truth may be relative though there is a concern for truth with a capital $\mathrm{T}$, and rules (but not necessarily laws) abound in the immediate social circles. Meanwhile, Sweden scores 29 on this dimension and has a very low preference for avoiding uncertainty [8].

Long-term orientation: China scores 87 in this dimension, which means that it is a very pragmatic culture. With an intermediate score of 53, Sweden does not express a clear preference on this dimension [8].

Indulgence: China is a Restrained society, as can be seen in its low score of 24 in this dimension. Communities with a low score in this dimension tend towards cynicism and pessimism. In contrast to China, Sweden has a high score of 78 in this dimension, which indicates that Swedish culture is one of the Indulgences. People in societies classified by a high score in Indulgence generally exhibit a willingness to realize their impulses and desires concerning enjoying life and having fun [8].

According to Hofstede's cultural dimension, we can see huge differences between China and Sweden. So, it will be essential to doing the cultural integration when operating the M\&A.

\section{THE CASE STUDY: GEELY'S ACQUISITION OF VOLVO CARS \\ The acquirer: Geely Enterprise}

Zhejiang Geely Holding Enterprise was established in 1996 and entered the automotive industry in 1997. Over the years, the company has developed 
rapidly, focusing on the automotive industry and technological innovation and talent training. After more than 20 years of development, Geely has gradually become a representative of Chinese private enterprises' bold pursuit of change and independent innovation. In 2001, China joined the World Trade Organization (WTO) and opened up passenger car production licenses to private capital. Geely has also successfully entered the automobile industry. Therefore, it focuses on automobile manufacturing and pays close attention to the innovation of automobile production technology and the cultivation of automobile talents. On December 24, 2009, Zhejiang Geely Holding Group and Ford Automobile reached a preliminary agreement on Volvo Cars' sale. On March 28, 2010, an equity transfer agreement was formally signed in Sweden, with a transaction price of approximately US $\$ 1.8$ billion, or about $\operatorname{HK} \$ 13,972.5$ million. Among them, US\$200 million were paid by bills, and the rest by cash. The funds come from Geely Group, Chinese and international capital. After that, Geely has developed very fast. In 2020, its total assets exceeded US $\$ 56.8$ billion, and it keeps maintaining a high growth rate.

\section{Target enterprise: Volvo Enterprise}

Established in 1927, Volvo is a well-known Swedish car brand. Volvo is highly praised for its high safety and product quality (especially its safety) worldwide. Volvo Cars are the most prominent car company in Northern Europe and one of the top 20 car companies in the world. Until June 2009, the company has 21,000 employees and nearly 2,500 retail stores worldwide. After purchasing by Ford, its sales have been declining for several years. Since 2005, the company has been suffering from more than 1-billiondollar losses every year. Facing the challenging situation, Ford company was eager to sell Volvo to other companies. Volvo is a car company with a few models, but it is unparalleled in terms of safety. In 1950, a department specializing in automotive safety research and development was established. Since then, Volvo has carried out significant innovations almost every year, and many inventions have become industry standards.

In 1999, Ford Motor Company of the United States bought the Volvo Cars business under the Volvo Group for US\$ 6.45 billion. In 2009, Ford of the United States sold its loss-making Volvo to China Geely. This "snake swallows the elephant" game has become a classic case in the history of cross-border mergers and acquisitions. The fact is that Geely's decision to acquire Volvo in 20010 was correct. After Volvo, the Swedish brand, relied on Geely to enter the Chinese market, from 2009 to 2018, Volvo Cars' global sales were twice as high as before, and sales in the Chinese market exceeded five times. In 2018, Volvo Cars' operating profit exceeded US $\$ 2.45$ billion, higher than the operating profit about US $\$ 1.5$ billion in 2009 , which is a giant leap forward.

\section{Geely and Volvo's corporate culture integration}

The cultural differences between Geely and Volvo are first manifested in national cultural differences.
Maintaining effective exchanges and cooperation under different cultural backgrounds will become a significant long-term issue for the two companies. Secondly, it is reflected in the target positioning of the two-car companies. Geely Auto considers the problems of economy and cost-effectiveness in vehicle manufacturing. It belongs to low-end cars, while Volvo focuses on safety, comfort, and green environmental protection, positioning high-end vehicles. Therefore, whether Geely Auto can learn from the advanced technology and the ability to transform Volvo's technology, and whether it will increase costs due to technology or strengthen Volvo's cost control and reduce Volvo's quality has become an essential focus of people's attention.

(1) Operate independently and realize "one enterprise, two systems."

Li Shufu proposed that "Geely is Geely, Volvo is Volvo, and the two are brothers, not a father-son relationship." Geely's management of Volvo is not a single control and suppression. Geely and Volvo's development strategies have formulated and retained Volvo's original management team, R\&D center, and production base. Therefore, Volvo has significant autonomy to handle internal affairs independently. It can decide on its business matters, consolidate employees' psychological contracts, rebuild organizational trust, and give Volvo respect and trust, weakening the estrangement and friction between the sides build a good communication environment.

(2) Restructure Geely's internal culture and strengthen dialogue and exchanges

The corporate mission of Geely Automobile is to "make the safest, most environmentally friendly and energy-efficient cars, and let Geely Automobile travel all over the world," which fully embodies the cultural integration with Volvo. Promote the value recognition between Volvo and Geely by establishing a talent exchange mechanism between the two parties. Geely has fully absorbed Volvo's business philosophy, values, and corporate culture, and on this basis, adjusted its management system and organizational structure to improve its management level. The "Volvo-Geely Dialogue and Cooperation Committee" was also established, which focused on several parts, like vehicle manufacturing, basic component design, new technology development, employee training, and so on. Both parties are concerned about promotes information sharing and provide practical, reliable transformation channels.

(3) Strengthen corporate culture management and research

Geely employs a professional cultural integration team to promote both parties' cultural integration to carry out corporate culture integration and regularly conduct cross-cultural training. Both parties fully understand each other's values and deep cultural background and reach a consensus. Geely attaches great importance to the protection of Volvo's brand. Based on retaining Volvo's original management team, Geely hires international management talents with rich cross-country management experience to manage Volvo and maintain Volvo's brand image. The 
establishment of a global corporate culture research center, strengthening international cooperation, specializing in developing integrated enterprises, expanding Geely's global vision, and improving global management capabilities and global corporate culture integration capabilities.

\section{CONCLUSION}

This article focuses on the crucial role of corporate culture integration in cross-border mergers and acquisitions. It provides suggestions for international M\&A basis on the case of Geely's acquisition of Volvo. After the M \& M\&A, Geely not only achieved the brand premium and successfully entered the global market with the help of Volvo's advanced technology and mature overseas sales network. In return, Volvo also acquired revitalization and thoroughly stimulating vitality and creativity based on maintaining the original target positioning. If Chinese enterprises want to "go global" and "go stable," they must pay attention to integrating corporate culture, which penetrates all aspects of corporate management and becomes an essential factor affecting the effects of mergers and acquisitions and corporate development. Chinese enterprises need to attach more importance to cultural integration to promote collective force and explore corporate cultural integration which is suitable for internationalization.

\section{REFERENCE}

1.Junichi Kato, Richard Schoenberg. The impact of post-merger integration on the customer-supplier relationship $[\mathrm{J}]$. Industrial Marketing Management, 2014, 43(2) : 335-345

2.Wenxing Sun, Pu Li, Chengcheng Li. Research on Human Resource Integration in Transnational Mergers and Acquisitions for Chinese Enterprises[P]. Proceedings of the 2018 International Conference on Advances in Social Sciences and Sustainable Development (ASSSD 2018), 2018: 522-527.

3.Liu Ang, Fu Shan-na, Xiao Zhen-hong. Study on risk assessment of overseas merger and acquisition knowledge integration based on character-weighted set pair[J]. ClusterComputing, 2019, 22(2): 52-58.

4.Maria E Botchkova. Critical success factors in the post-mergers and acquisitions information technology integrations[D]. Massachusetts Institute of Technology, 2017: 220-224.

5.Hu Ting, Wang Jikang. Do Chinese companies' overseas mergers and acquisitions enhance company value?- Take Geely's acquisition of Volvo as an example[J]. East China Economic Management, 2014, 28(02): 155-159.

6.Liang Yanjun. Cultural Integration in Chinese Enterprises' Overseas Mergers and Acquisitions[j]. Chinese \& Foreign Corporate Culture, 2016(11): 65-67.

7.Zhao Xiaoying. The Value Evaluation of Synergy Effect of Auto Enterprise M\&A[D]. South China University of Technology, 2019.

8.Hofsted insight[EB/OL]. www.hofstedeinsights.com

\section{STRATEGIC DIRECTIONS FOR THE SUSTAINABLE DEVELOPMENT OF THE REPUBLIC TOGOLESE}

DOI: 10.31618/ESU.2413-9335.2021.3.85.1329
Malacoubame Kolani,
Hanchar Andrei I.

\section{ABSTRACT}

The transition to sustainable development is impossible without a solution to the country's waste management problem. In addition, the achievement of the objectives of the Togolese Republic's transition strategy towards sustainable development determines the need to meet the main challenges. This is due to the reduction in the amount of Class 2 hazardous waste, represented by used batteries and used battery acid, the types of waste formed in most cases, are caused by people with a waste-producing activity of less than 50 tons per year (about 400 subjects of economic and other activity). Based on the above, we can say that the main priority axes of transition of sustainable development of Togo must respect the condition of greening economic processes, which will improve both the quality and the standard of living of the population, preserve and protect the ecology in the regions. The development of such a direction as agro-ecotourism makes it possible to comply with this requirement and fully comply with the principles of sustainable development. Then, for a more detailed study, we will evaluate the development of agro-ecotourism in the regions.

Keywords: sustainable development, environmental safety, EUROSTAT, emissions of pollutants, recycling, waste management problem, Agro-industrial, tourism activities, wood waste.

The socio-economic state of the Republic of Togo is closely linked to the environmental restrictions that exist in the territory of the West African sub region, which also includes Togo.

The country is characterized by low representation of leading industries such as: mechanical engineering, Metallurgy, electricity, etc. The promising directions of the development of the regions are defined by the Agrofood and tourism activities. The adoption of a sustainable development policy by the state requires the authorities to address important socio-economic issues. The goals of prefectures in the context of environmental safety, which, in turn, determines the transition to innovative production systems, energy consumption, resource conservation and the search for new ways of development of the territory. 